\title{
Self-Reflections in a Personal Space: Investigating the Process of Self-Portrait Painting by Academic Research
}

\author{
Assistant Prof. Dr. Mohammed Baker Mohammed Al-Abbas (Corresponding author) \\ The University of Jordan, School of Art and Design, Department of Visual Arts \\ m.alabbas@ju.edu.jo,mohdbaker83@hotmail.com, mohdbaker83@gmail.com \\ Rawan Mustafa Khaleel Abu Hammad \\ Independent Researcher in Information and Communication Technologies \\ rawanabuhammad1991@.gmail.com
}

Fatima Mahmoud Mohammad Al-Tawalbeh

The University of Jordan, School of Art and Design, Department of Visual Arts

f.tawalba@ju.edu.jo, fatima t83@yahoo.com

\author{
Dr. Mariana (Mohammed Amin) Mahmoud Al-Alawneh \\ Independent Researcher in Vocational Technologies and Methodologies \\ alawnehmariana8@gmail.com
}

Associate Prof. Dr. Yahya Salim Suleiman Issa

The University of Jordan, School of Art and Design, Department of Theater Arts dryahya bashtawi@yahoo.com

Assistant Prof. Dr. Naser Yousef Ahmad Jawabra

Palestine Polytechnic University, Collage of Admin. Science and Informatics, Multimedia department njawabra@ppu.edu, nsr_obstract@yahoo.com

\author{
Abed Farhan Obed \\ Scientific College of Design, Fine Arts Department and Ph.D. Candidate in Fine Arts Studios, Faculty of Art \\ Computing and Creative Industries, Sultan Idris Education University \\ abedobed32@gmail.com
}

Rao Tahir Anees

Ph.D. Candidate in Management, Limkokwing University of Creative Technologies

aneesrao82@gmail.com

This paper is a practical outcome of a multidisciplinary research project conducted by the authors on the contemporary and modern practices of the Improvisation in Arts. All the authors are research-oriented practitioners in the fields of visual arts, performance arts, multimedia, Information and communication technologies as well as vocational training. Furthermore, the drawings, paintings, and sketches are all made by the correspondent author Assistant Professor Dr. Mohammed Baker Mohammed Al-Abbas as part of his researchoriented artistic practice through the hybrid painting techniques.

\begin{abstract}
The purpose of this practice-based paper is to investigate the artistic reflections and self-aesthetics into the process of artwork making. Every stage of this process represents a particular significance from the initial stage to the finishing stage. Furthermore, this exploration aims to develop the employment of practical research in the field of Visual Arts on personal, communal and institutional levels. In this exploration, the methodology is the vehicle that transforms the research into reality. Making the artwork itself is the methodology, and this process is the primary reference of the present research. Therefore, the author presents the synthesis of the artwork making rather than the analysis of its aftermath, the focus in this context is the construction of the artwork. This is the result of this research, the artwork itself. Regarding the employability aspects of this approach, it involves the practitioners and
\end{abstract}


researchers in the fields of the visual arts toward further realizations of the actual creative process. This employability takes place into the signs of progress on different levels through academic and artistic practices in schools, universities as well as higher learning and teaching institutions. The present practical paper is significant because it investigates reflections of the cultural identity as well as the narratives of personal memory into academic research. In the multicultural present temporality, research-oriented artists highlight the diversity of their societies and represent significantly personal aesthetics as themes in their artworks. This approach would elevate the mutual understanding among people from different aesthetical backgrounds; people's trends enhance multicultural perceptions, harmony, and coexistence. In addition, artists in this regard illustrate such an approach in their visual art when they compose practice and research with the symbolic content, which reflects social motives. Artists practice such art to critique the violent content in communication media and educate people that media may fake reality to create more audience and viewers. This study focused on the significance of subjective representations in contemporary arts, and the impact of such representations on the mutual understanding among people of multicultural societies.

Keywords: Contemporary Art Practice, Studio-Based Methodology, Practice-Based Research, Hybrid Painting Techniques, Multimedia, Mixed media, Photography.

DOI: $10.7176 / \mathrm{JEP} / 11-12-18$

Publication date: April $30^{\text {th }} 2020$

\section{Introduction}

The current research employs the method of practical experimentation (Practice-Based Research) within the making process of the self-portrait. The artist/author creates the composition of pictorial artworks through a set of self-observations as the subject of this research. In addition to painting self-portrait, the author indicates the painting phases and temporalities while the study distinguishes between the creative practice of visual arts and the creative practice of reflective art criticism, which depends on the act of writing rather than the act of painting. Therefore, this research depends on the process of art-making while documenting its temporalities through the act of creative writing (Borgdorff, 2011; Savin-Baden and Wimpenny, 2014; Gray and Malins, 2004).

The pictorial composition refers to the structural process in the art of painting. It depicts the details of the visual evolution and the process of aesthetical construction into the artist's inventive style (Janson, 2007). In this context, visual artists observe novel cultures capturing the instance of the metaphorical artwork, the visual elements, the graphic space, perspective, as well as pictorial vibrant painting surfaces. Dramatically, the sense of the moment influences the art of painting, specifically, when artists investigate different cultural identities and express with high individuality their arts and beliefs in harmony. They intentionally critique the global brutality that is breaking down the human culture into parts and engage deeply with their own cultural, social and political issues. Artists' engagement is a daily practice that is highly exposed to the electronic social reality which is the phenomenological characteristic of our current global culture. This emerging energy into the contemporary visual culture made a clear impact on the art practices of today's artists, driving them to elaborate into academic investigations.

This paper aims to highlight the aesthetic representations of artistic individuality in contemporary painting. Artists articulate spiritual values into art venues in an international context and create a constructive dialogue between cultures based on the philosophy of understanding others. In contemporary art there are various examples of symbolic representations of spiritualities and aesthetical themes (Grovier, 2015); they express the human state of affairs as well as multicultural aesthetics. The thematic representations of people's values are a cultural phenomenon that has a deep cultural identity, and at the same time interacts actively with the global culture. The phenomenon of subjective reflective aesthetics in art represents three major characteristics in the contemporary civilization that are the diverse cultural backgrounds of society, global exposure, and social knowledge in contemporary contexts.

\section{Methodology: The Practice-Based Investigation into the Artwork making}

In this practice-based paper, the methodology is based on practical experimentation. This method depends on two basic components, which are the act of making artwork and the act of recording the process of this making in reflective research. The importance of this methodology extends through the integration of research and art practices to record the process of art-making. Furthermore, this methodology stands on locating and signifying the stages of creating and making artwork to shed light on a variety of research and creative productions (Borgdorff, 2011; Savin-Baden and Wimpenny, 2014; Gray and Malins, 2004). Practical research through this methodology becomes a temporal event, into which, each stage signifies personal, symbolic, and aesthetical meaning. This research methodology focuses on the assembly of the artwork and the research process, through which the artist is the researcher. 
This methodology is significant because it explores artistic practice as aesthetic thought on the individual and social levels. In this context, the artist as a researcher presents the performance of producing art as a consciousness practice that transforms into research. This framework of research and contemporary art practice synthesizes theory and practice, which moves forward for a deeper understanding of the creative process and its temporal stages (Savin-Baden and Wimpenny, 2014). Practice-based research frames the performances of visual narratives into a continuous motion over time. This complex creative process records the reflections of the individual in a comprehensive, transportable and progressive society in the details of the artwork and research, as it is a dynamic process of producing knowledge and art together.

\section{The Artwork: Self-Reflections in a Personal Space}

The current part of this investigation is divided into two main sections, the first section (A.) presents the studies, sketches and visual diaries that I made (the Author's/Artist's voice) before I started the actual painting with a hybrid technique on a $120 \times 160$ centimeters canvas using mixed media and acrylic paints, which appears in the second section (B.) of this part. The second section (B.) presents the actual final artwork discussing it by a textual written reflection. This part (with both sections $A$. and $B$.) identifies the method of representing the process of the artwork making whether it was a sketch, painting or a visual diary in its final status or presenting it during the process of its making. The first section (A.) presents the booth statuses while the second section $(B$.) presents only the final status of the artwork. I made this division because the process is a significant source of visual experience and self-reflection. And the final stage of the artwork is also a significant state of the art that evokes its self-identity and its artistic independence.

\section{A. The Process: The Temporalities Before Starting the Actual Artwork}

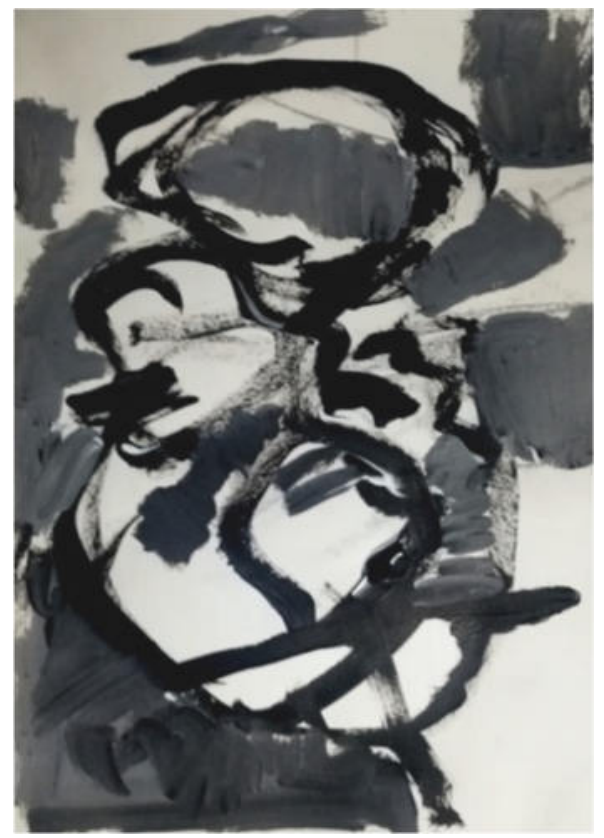



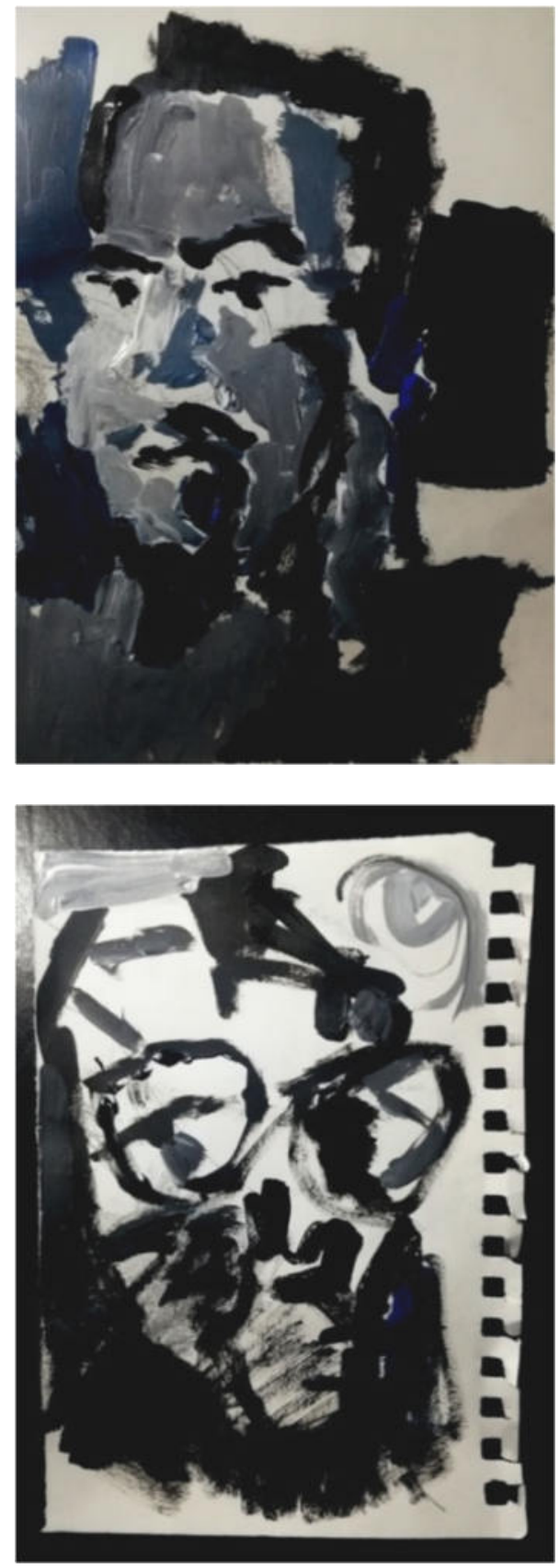

Figure 1. Random Sketches through a Visual Diary, mixed media on paper, 20 X $14 \mathrm{~cm}$ each. 

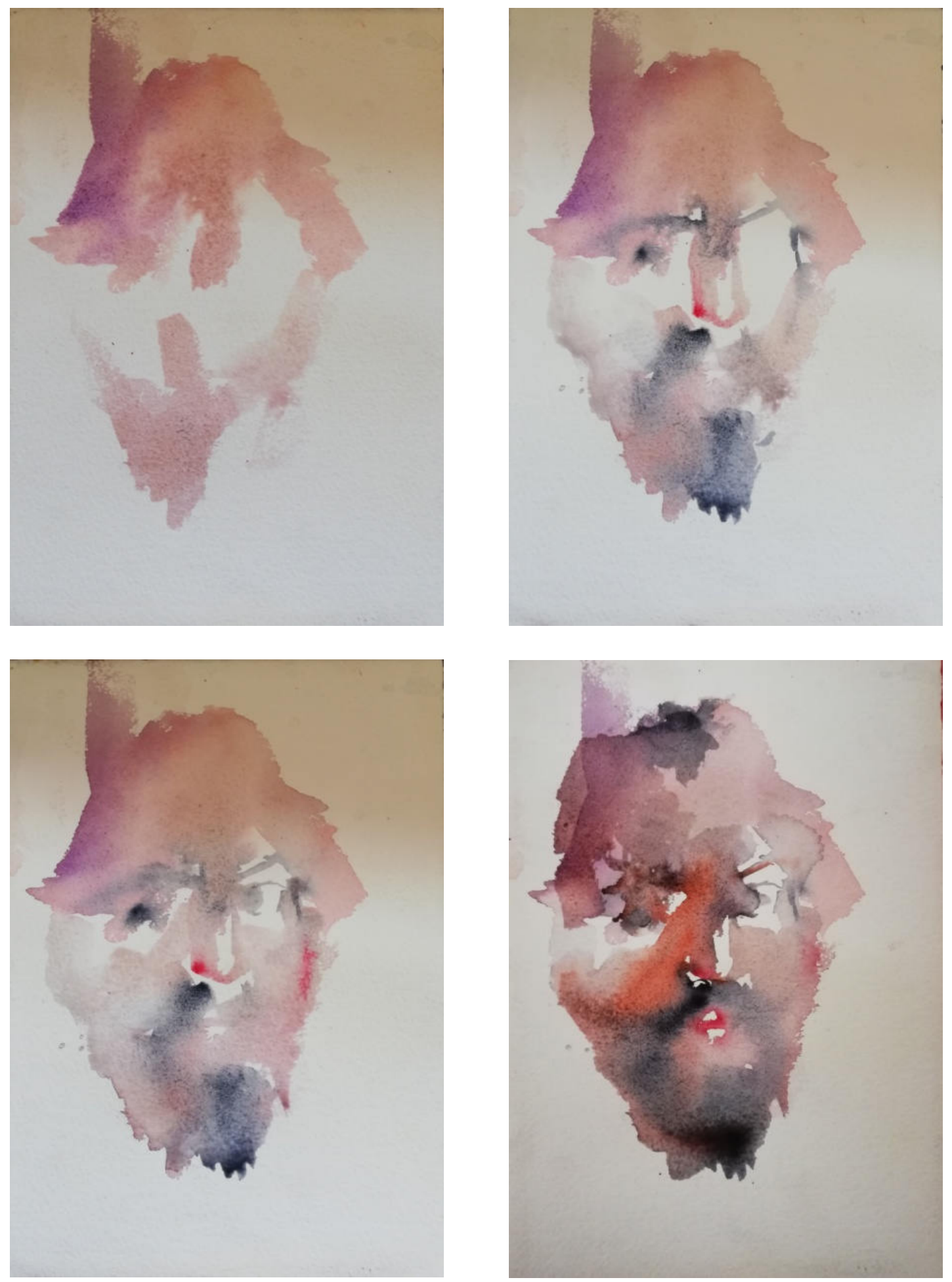


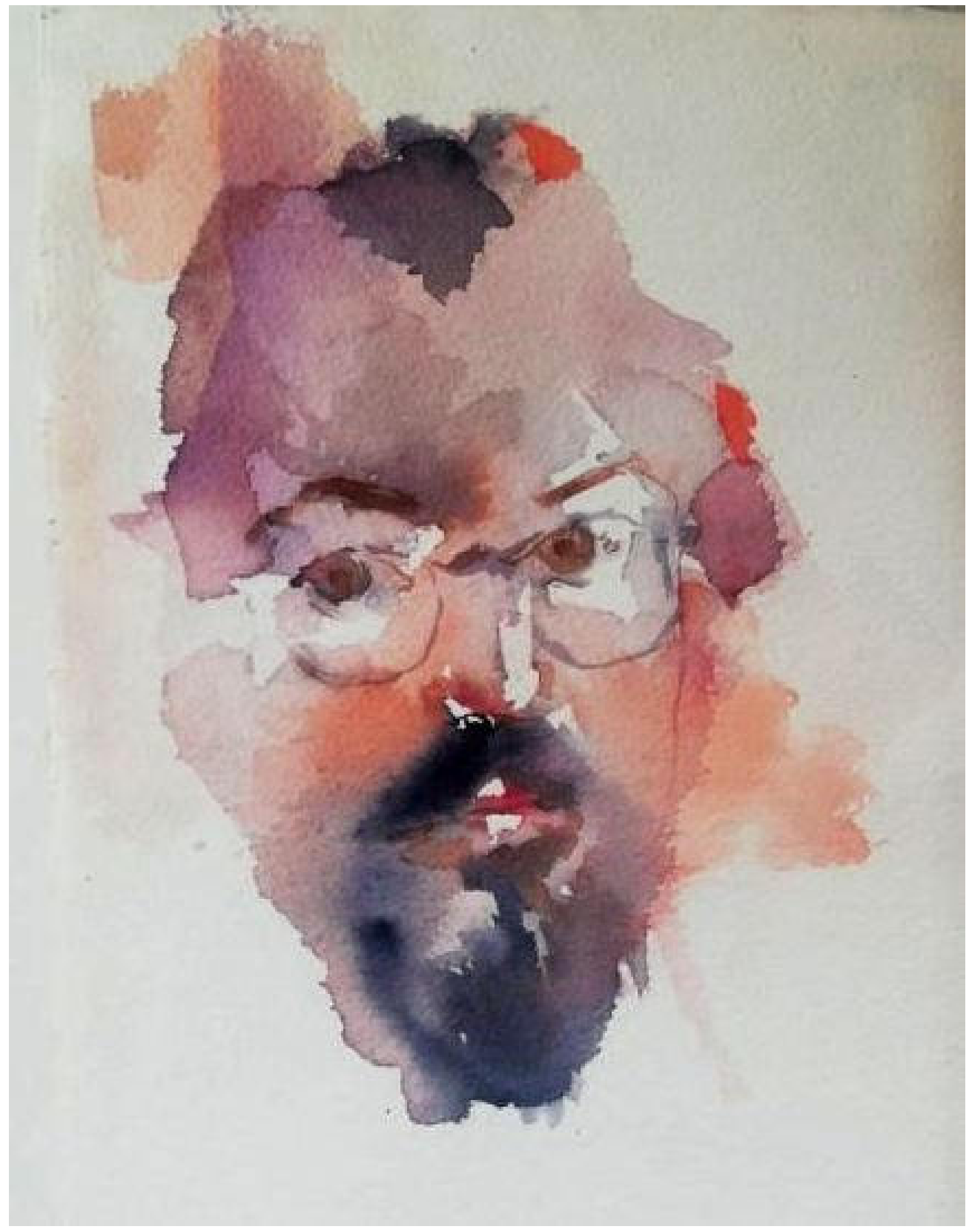

Figure 2. Self-Portrait in a Creative Journal, watercolors, 29 X $19 \mathrm{~cm}$. 

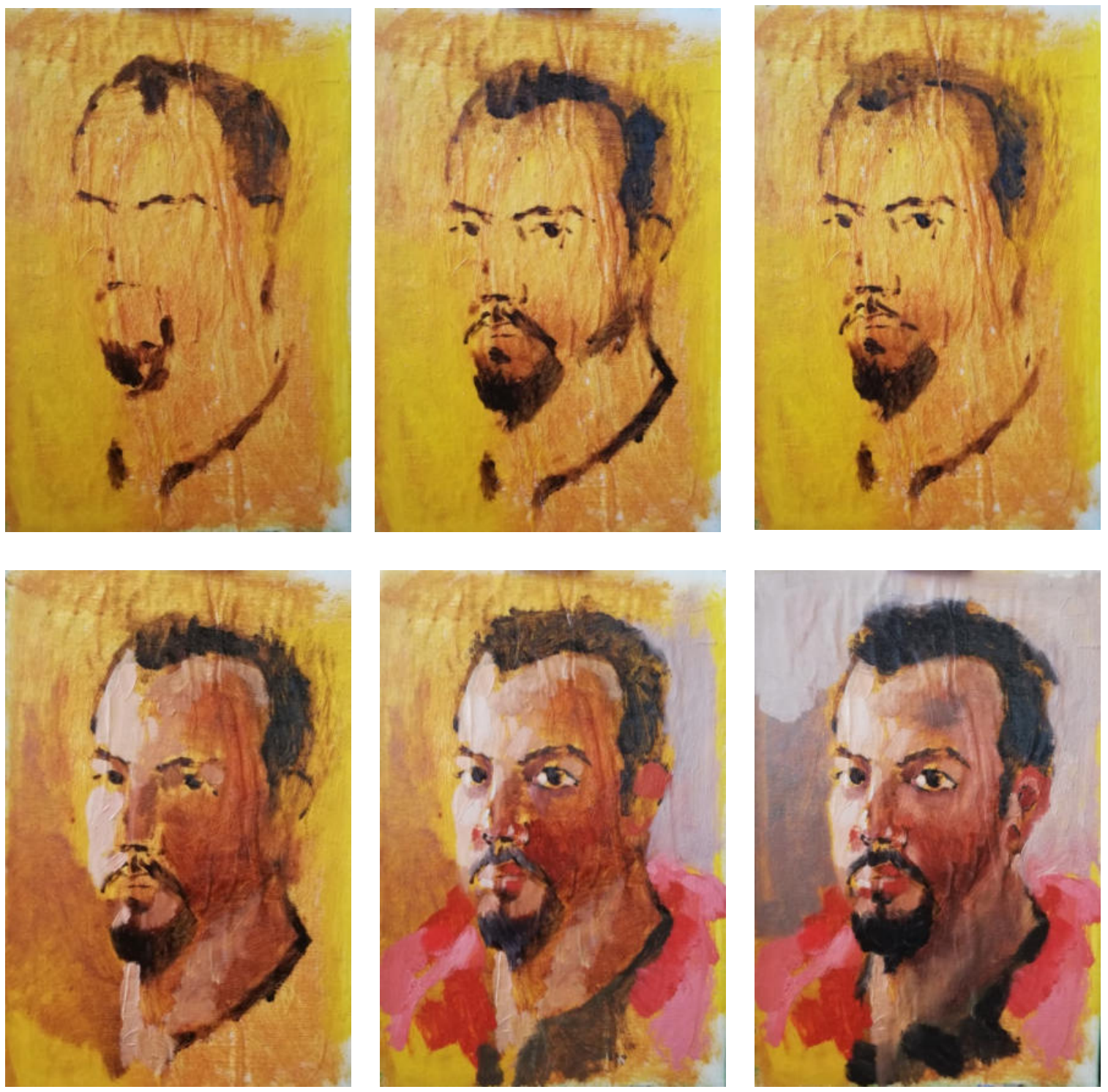


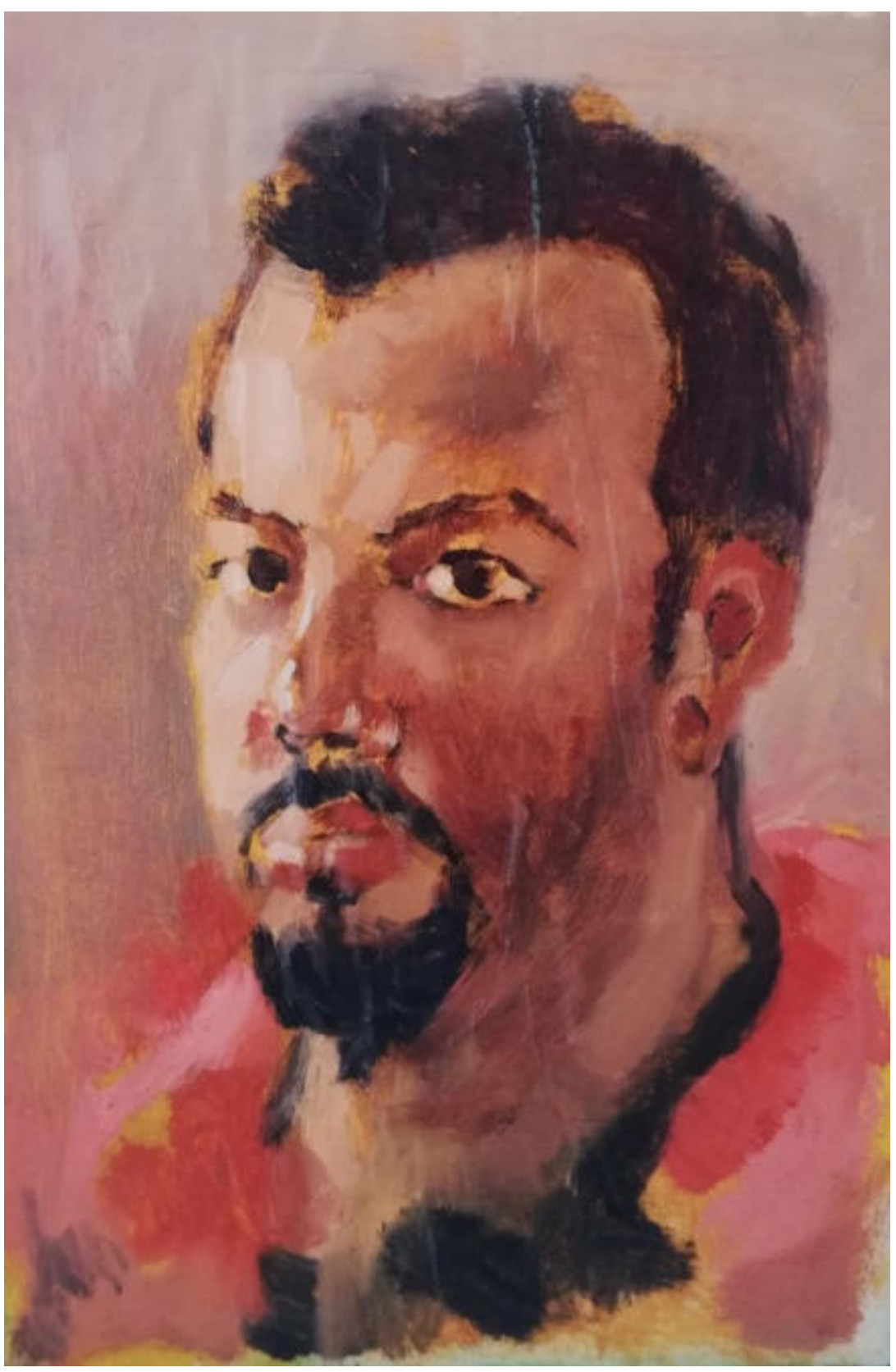




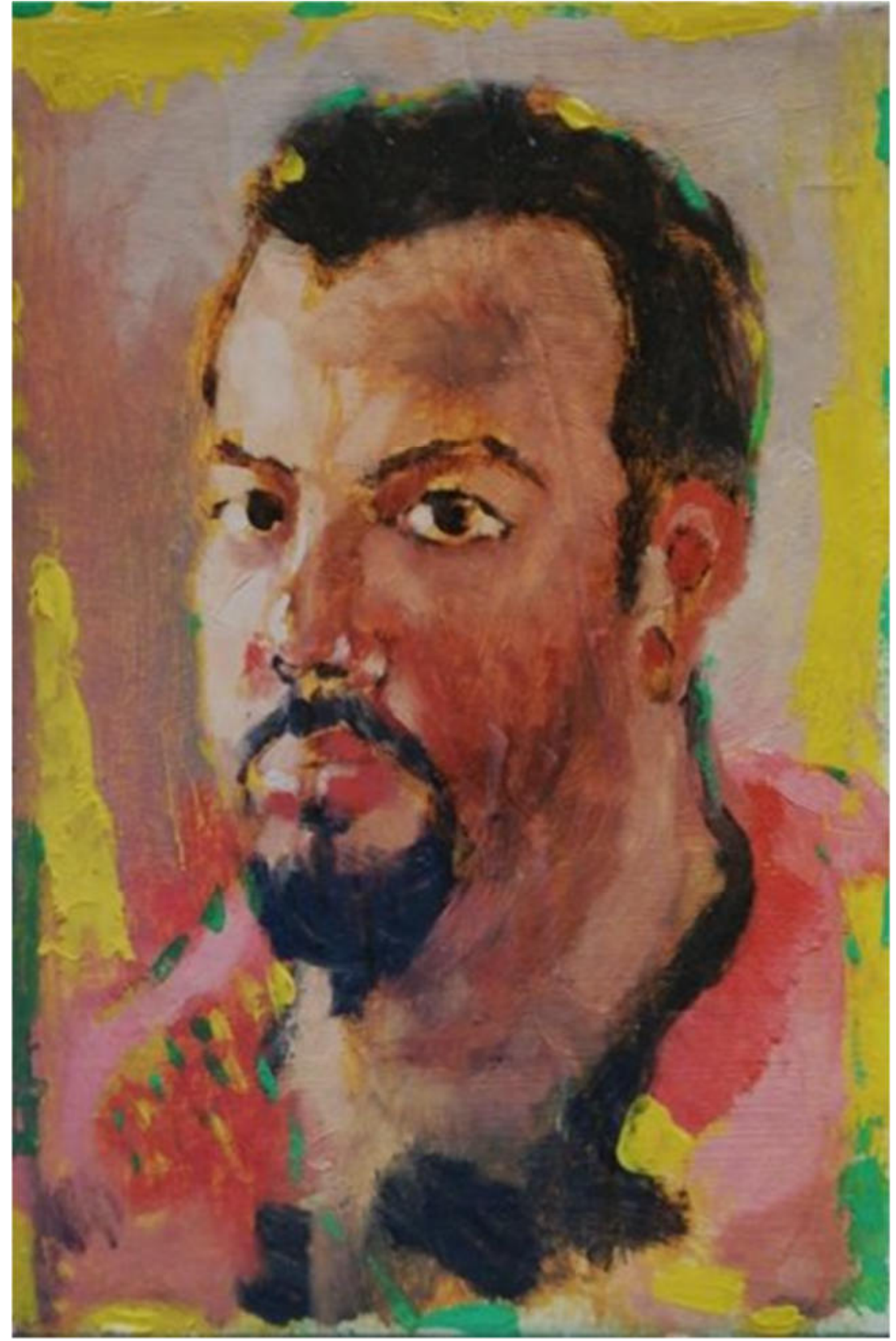

Figure 3. Self-Portrait in a Creative Journal, hybrid technique and oil colors on mixed media, 29 X $19 \mathrm{~cm}$. 

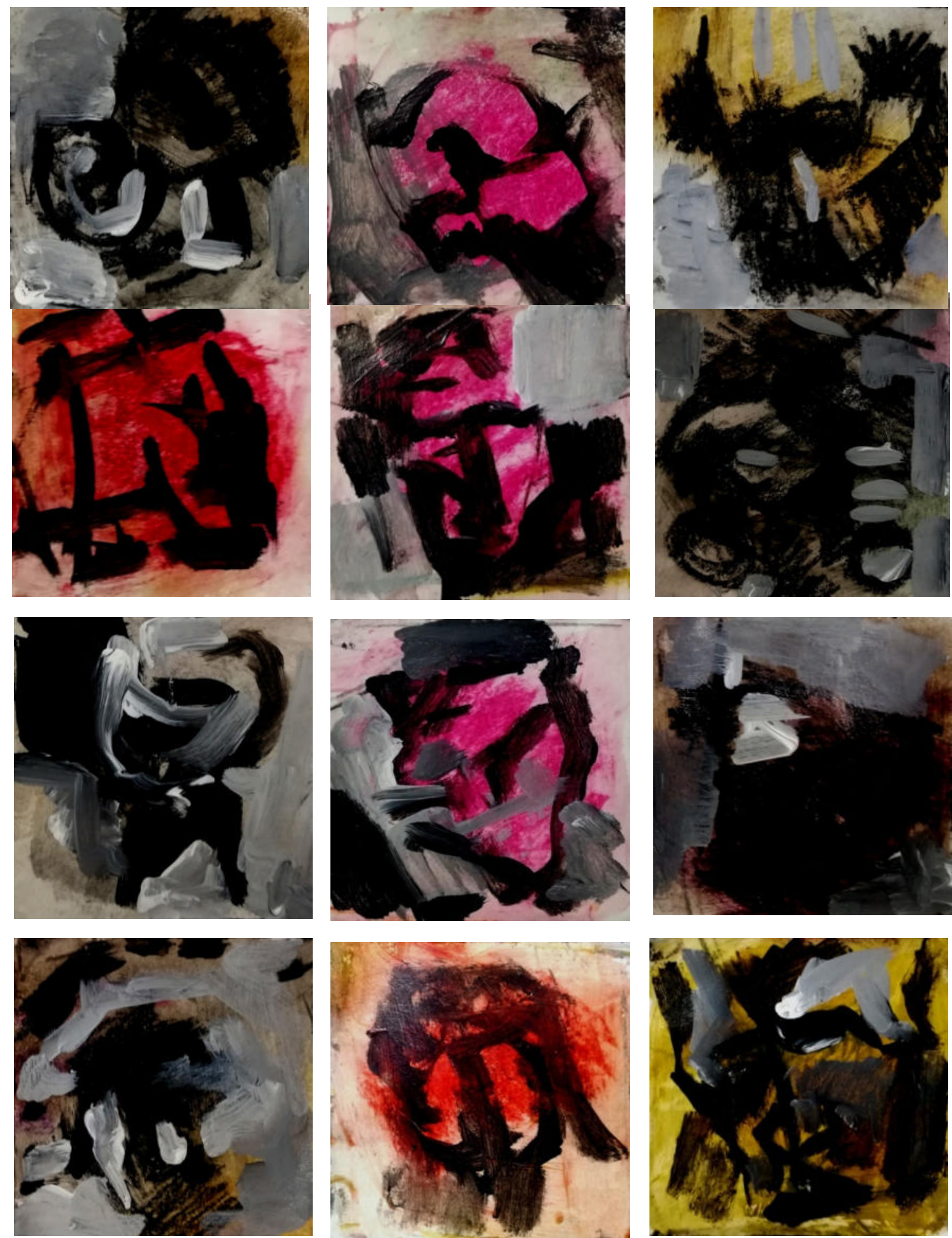

Figure 4. Random Sketches, hybrid painting technique and mixed media on paper, 8 X $8 \mathrm{~cm}$ each. 


\section{B. The Final Stage of the Actual Artwork: Self-Portrait and Self-Reflection}

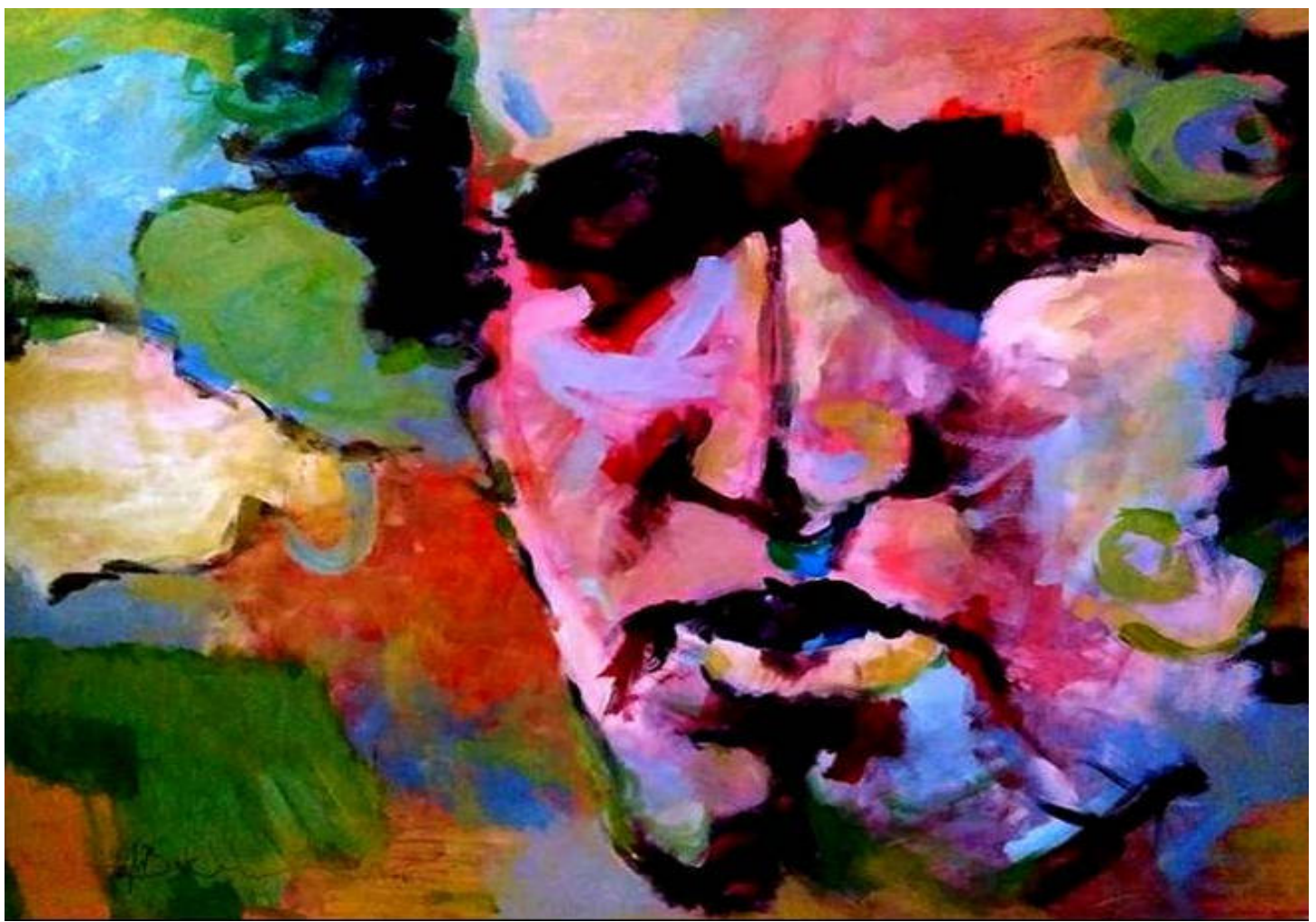

Figure 5. Self-Reflections in a Personal Space, 2018, 120 X $160 \mathrm{~cm}$, hybrid painting technique and mixed media with acrylic paints on canvas.

In the global context, politics, clashing economies and beliefs provided new concepts for research-oriented artists to restructure the world, where new categories are replacing the conventional categories into the consideration of local culture and people's ethnic identities. Cultural knowledge makes a balance between global values and local values, affecting the contexts of the artistic process.

My artworks of abstract portraiture explored the connection between art and commonplace urban elements in the current and past spaces of the cities. The practice of understanding art combined my visual narratives of the places with a nostalgic interpretation of the portraits and people's faces that I encountered through such urban spaces. The direct expression on the painting surface is my tendency to filter differences across the common objects and symbolic icons. The style of expressionist abstract painting produced a multicolored impact, where the pictorial compositions echoed the discursive and massive fusion between the human forms and urban elements.

The theme of the human face corresponds with the self-surrounding architecture in my pictorial compositions. The arrangement of the abstract masses re-created the urban spaces, perspectives, body movements as well as nostalgic textures, traces and marks of people you may know or you may forget. The compositions produced enigmatic expression in the paintings, apparently perpetual fields of visual dialogue in which the human body repeated oneself into another architectural form.

My visualization of this concept depends on what I critique as urban portraiture through tracing the faces of the people in the powerfully structured abstract composition to feature the fusion between the conception of human appearance and architectural and urban surroundings. That constrained the current social reality, which influenced the collective memory as well as the cultural identity of the people.

This artwork records the relationship between the popular urban temporality and people who live within these urban spaces. The compositions in the artworks produced forms that combined human bodies and houses, streets, 
gardens, and shops. Every artistic intention is unique, composed contemporaneously to resemble the pictorial compositions in my paintings. Representing the personal identities in a world controlled and surrounded by monstrous cement masses is a creative practice of art.

Identity versus anonymity is the feature of contemporary culture that appears in my pictorial compositions. These representations articulated in a constructive abstract and expressive composition. The dynamics of the tones are coercive. The organization is a visually complex intercommunication between the human body, identity and nostalgic memory on one hand, and on the other hand, the concrete, inhumane, and rigid urban spaces.

In this practice-based investigation, I transformed myself into a wondering soul, to think like someone else and to act like a stranger. In this particular context, my visual research evolved through the conception of selfinvestigation on personal spaces and their daily metamorphic temporalities. The urban spaces are saturated with an unlimited variety of concrete structures that engage significantly with our daily practices. The critical approach over this reality negotiated the aesthetics of contemporary spaces in the city. In other words, it presented an idea on the confusing reality of the urban city where people transform from cultural identity to another.

\section{Conclusion}

The present paper is a record of personal practice. In other words, it is an investigation that occurred through the process of artwork making. The focus of this approach depends on the act of doing, making and creating, which makes the result recorded in this paper (which is the artwork itself) a primary source specifically with regard to the routine of citing and referencing. This paper is an experiment that simulates the creative process of the practicing artist (American Psychological Association, 2010); therefore, the practical experimentation, activities, and knowledge do not oblige the author, in general, to cite secondary resources in the text or in a list of references. The study itself is a record of this experience, based on creative action and creativity and not on knowledge deducted from references and secondary resources such as books and articles, so the artwork is part of the researcher's personality and voice.

This paper presented the impact of the artist's subjective reflections on personal artistic practices. It demonstrated the thematic representation of self-conviction as a characteristic feature in contemporary art where the artists expose art to a multicultural audience. This audience is well educated to accept differences among society and understand it because the multicultural practices in society deliver further powers to visual arts. This conceptual approach in research enhances the significance of the plural structure of cultural identities into one community. Artists' vision lead to new incites of cultural understanding, where concepts became diverse and individual in local and global levels, this presents more grounds to new experiences and new ideas on contemporary arts to the audience, through a constant dialogue between the international artist and the local viewer.

\section{References}

[1] American Psychological Association. (2010). Publication Manual of the American Psychological Association (6th ed.). Washington, DC: Author.

[2] Borgdorff, H. (2011). The Conflict of the Faculties: Perspectives on Artistic Research and Academia. Netherlands: Leiden University Press.

[3] Ficher- Rethus, L. (2004). Understanding Art ( $7^{\text {th }}$ ed). USA: Wadswarth/ Thomson learning.

[4] Janson, H. w. (2007). Janson's History of Art ( $7^{\text {th }}$. Ed.). USA: Pearson Education, inc.

[5] Savin-Baden, M. and Wimpenny, K. (2014). A Practical Guide to Arts-related Research. Rotterdam, The Netherlands: Sense Publishers.

[6] Stokstad, Marjilyn.(2005). Art History (2ed. Ed.). USA: Pearson Education,inc.

[7] Walther,I. F. (2006). Impressionism (Michael Hulse, trans.). Germany: Taschen.

[8] Gray C. \& Malins J. (2004) Visualizing Research: A Guide to the Research Process in Art and Design. Ashgate Publishing Limited: Hants, England.

[9] Grovier, K. (2015). Art Since 1989. New York: Thames and Hudson.

[10] Nanjo, F. (2006). Belief: Singapore Biennale 2006 (biennale catalogue, 4 September to 12 November, 2006). Singapore: National Art Council.

[11] Nanjo, F. (2008). Wonder: Singapore Biennale 2008 (biennale catalogue, 11 September to 16 November, 2008). Singapore: National Arts Council.

[12] Joo, E., Keehn II, J. \& Ham-Roberts, J. (2011). Rethinking Contemporary Art and Multicultural Education. New York: Routledge. 